\title{
Bringing the Field to Students during COVID-19 and Beyond
}

Leilani A. Arthurs, Dept. of Geological Sciences, Univ. of Colorado at Boulder, 2200 Colorado Ave., Boulder, Colorado 80309, USA

\section{BACKGROUND}

Undergraduate field-based experiences are valued components of geoscience education (Hendrix, 1967; Petcovic et al., 2014). However, the belief that it is "impossible to simulate [field] situations ... to make ... structural, stratigraphic, geomorphologic, lithologic, etc. observations in solving a single problem" (p. 161, Hendrix and Suttner, 1978) means widespread efforts to make field experiences more accessible to students are missing, which results in a culture of exclusion. The COVID-19 pandemic is forcing educators to re-think how to design field courses. This article describes first-hand experiences tackling the "impossible" to support students graduating on time and provide an instructional design model for post-pandemic field education that is more physically accessible than traditional models of field instruction.

\section{INSTRUCTIONAL DESIGN GOALS}

Scheduled to teach the "Introduction to Field Geology" course for the first time during the COVID-19 pandemic, I was given the choice to cancel or teach remotely. I chose the latter. My first instructional design goal for this remote version of the course was for it to, as much as possible, be the same as the inperson version I would teach in the future. From this first design goal emerged three others. Students should be able to remotely (1) explore the field environment independently and not be strictly prescribed where to stop, what to look at, and what questions to ask and answer; (2) work with digital renditions of real geologic environments, not animated or contrived environments; and (3) visit local field sites. In short, my motivating design goal was to bring the field to the students because I could not bring them to the field.

\section{INSTRUCTIONAL DESIGN METHODS}

The primary focus of this article is the technologies used to bring local field sites to my students. Students were reminded that this field course was being taught remotely due to the university's COVID-19 policy for summer courses. We also discussed the fact that geologic fieldwork is often conducted remotely today using a variety of visual data. Thus, they would have opportunities to develop essential skills applicable to both onthe-ground fieldwork and remote fieldwork.

Three cameras captured visual data to bring the field to the students for all field assignments in this course: standard GoPro camera, Insta360 Pro camera, and digital SLR camera. The GoPro captured continuous wide-angle videos along each traverse, which students viewed first to do a general reconnaissance. The Insta360 Pro camera captured high-resolution $360^{\circ}$ panoramic digital images (referred to as "panos" hereafter), which students viewed second using free PTGui software that converted panos into $3 \mathrm{D}$ virtual-reality settings in which students could turn around and look up and down in any direction, zoom in and out of any field of view they chose, and independently explore the environment. The panos were taken at locations along each traverse where rock exposures were least obscured by vegetation. Each field assignment had six to seven pano sites, but only three were plotted on the provided contour map with each assignment. The plotted locations served as anchor sites for orientation purposes. To practice self-location, students plotted the remaining pano sites. Northpointing plastic markers were laid around the base of the Insta360 Pro camera during the capture of each pano, and students were instructed to use them as substitutes for using a compass in the field to find north.

Additionally, panos had yellow plastic number tents at random locations so students could use these markers as common points of reference while talking with each other and me about their field observations (Fig. 1).
A 100-m measuring tape was laid along many traverses, and a photo was first taken of the measuring tape and then of a yellow plastic number tent to aid students in developing a sense of distance and scale. After watching the GoPro videos and exploring the $3 \mathrm{D}$ virtual reality panos, students then viewed standard high-resolution 2D photos taken with the SLR camera. These photos contained yellow number tents with printed ruler gradations at their base and rulers or other objects for scale to aid students in making and describing observations. Field assignments were posted in Canvas for students to download. Students accessed all visual data from a Google Drive folder and downloaded the $360^{\circ}$ panos to their personal computers to view with the PTGui software. Students used the CamScanner phone app to scan their completed field notes for each assignment and uploaded them to Canvas for instructor review and grading.

\section{LEARNING GOALS}

In designing this course with the intentions to (1) immediately teach it remotely and (2) teach it in person in the future, I initially articulated six course-level learning goals. By the end of the course, students should be able to: (1) work independently and work collaboratively while pulling their own weight; (2) know the meaning of pertinent field geology terms and facts; (3) observe features and processes in the environment and describe observations in individual field notes and oral presentations; (4) make sense of "the field" through reasoned thinking of observations; (5) know the differences between inference, interpretation, and hypothesis as well as develop and test them as appropriate; and (6) use a Brunton compass and Jacob's staff. The sixth goal was a challenge for remote instruction. Departmental deliberations about whether to insure and mail students field equipment determined students

GSA Today, v. 31, https://doi.org/10.1130/GSATG478GW.1. CC-BY-NC. 


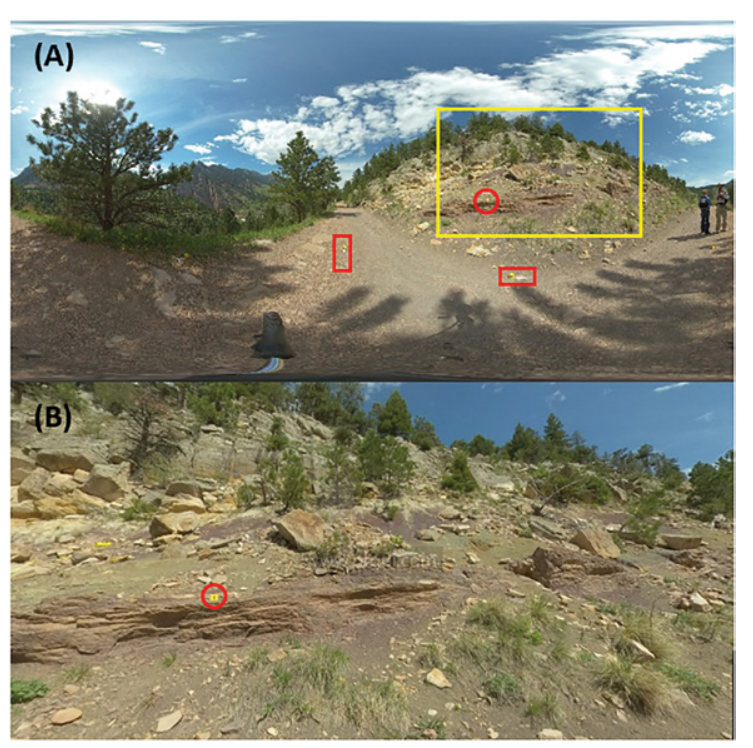

Figure 1. Insta360 Pro panorama. (A) Viewed in Microsoft Photos as a flat, 2D image. (B) Viewed in PTGui as 3D virtual reality in which one can zoom in/out, look up/down, and turn left/right. Yellow rectangle in $(A)$ represents the field of view shown in (B). Red circles show the location of a plastic yellow number tent. Red rectangles show locations of north-pointing markers.

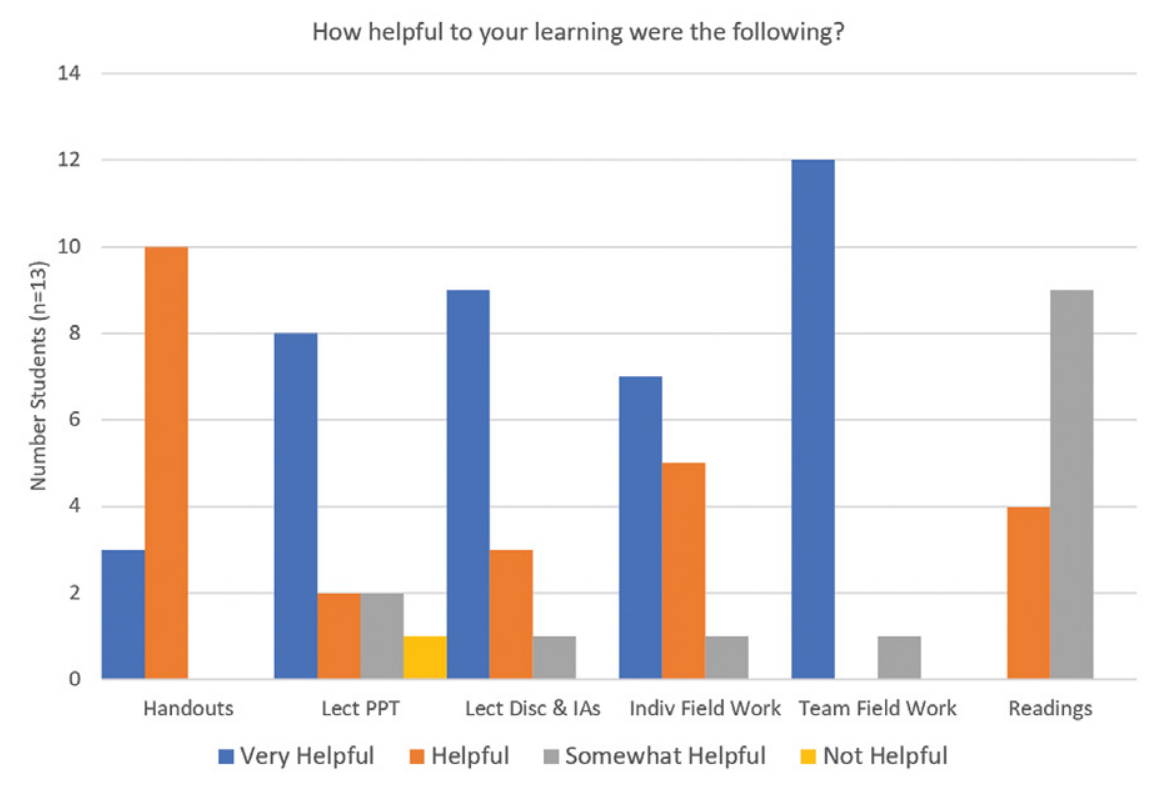

Figure 2. Responses to item on end-of-course questionnaire. IAs-in-class activities; PPT-PowerPoint. would learn how to use the equipment in upper-division courses as needed and, meanwhile, learn how to measure strike and dip using ROCKD (a phone app).

\section{LEARNING OUTCOMES}

Field assignments were designed so that components were independently completed prior to team-based work, which took place in Zoom breakout rooms. In an end-ofcourse questionnaire, all but one student (12 out of 13) found the team fieldwork "very helpful" to their learning (Fig. 2). The results of a pre- and post-instruction test revealed dramatic improvement in students' knowledge of field-related geologic terms, including being able to differentiate between observations, inferences, interpretations, and hypotheses. Students' field notes and PowerPoint presentations were not only part of each field assignment, they were formative assessments that revealed overall improvement in students' ability to, for example, describe what they see and draw inferences from those observations.

\section{LESSONS LEARNED ABOUT THE IMPOSSIBLE}

Simulating the field environment was previously believed impossible; however, technological advances made it possible to bring the field to my students in a way that satisfied all my instructional design goals and helped students achieve all but one of the course-level learning goals for an in-person version of the course. Additionally, students stated that not contending with physical aspects of field work (e.g., traversing uneven ground, coping with extreme heat, etc.) helped them focus on developing cognitive and teamwork skills they will use in any field location. The model of remote field instruction developed and implemented in May 2020 is one way of supporting current students during the pandemic and of increasing the accessibility of field courses to future students across a range of physical abilities.

\section{REFERENCES CITED}

Hendrix, T.E., 1967, NAGT looks at summer field courses: Journal of Geological Education, v. 15, no. 2 , p. $73-77$, https://doi.org/10.5408/0022 -1368-XV.2.73.

Hendrix, T.E., and Suttner, L.J., 1978, An assessment of field courses in geology: Journal of Geological Education, v. 26, no. 4, p. 160-164, https://doi.org/10.5408/0022-1368-26.4.160.

Petcovic, H.L., Stokes, A., and Caulkins, J.L., 2014, Geoscientists' perceptions of the value of undergraduate field education: GSA Today, v. 24, no. 7, p. 4-10, https://doi.org/10.1130/GSATG196A.1.

Manuscript ReCeived 18 July 2020

ReVised MANUSCRIPT RECEIVEd 23 OCt. 2020

MANUSCRIPT ACCEPTED 12 Nov. 2020 